\title{
TENSÕES ENTRE GÊNEROS NA CLASSE POPULAR: UMA DISCUSSÃO COM O PARADIGMA HOLISTA*
}

Tania Salem

Entre l'homme et la femme, il y a quelque chose que ne marche pas.

(Lacan)

\section{Introdução}

Uma importante produção antropológica desenvolvida no Brasil sobre as classes trabalhadoras urbanas postula a irredutibilidade de suas especificidades culturais, e sugere que seu sentido contrastivo em face da cosmologia dos segmentos médios (sobretudo na sua versão letrada e psicologizada) encontra expressão na oposição dumontiana holismo/individualismo. ${ }^{1}$ Ter-se-iam, em um pólo, os "individualistas modernos" que, norteados pelo princípio da igualdade (i.e., da aversão a englobamentos) subordinam o todo às partes e a relação ao indivíduo-Valor. No outro pólo estariam os grupos populares que, comprometidos com o ideal da hierarquia, enfatizam antes totalidades sociais do que unidades individuais e têm na relacionalidade, na complementaridade e na reciprocidade as qualidades afirmativas de sua cultura.

As particularidades dessas configurações morais especificam-se, embora não se esgotem, na forma e nos significados que cada uma delas imputa à relação entre gêneros e à sexualidade. Alega-se que nós — os "individualistas-modernos" - segmentamos o sexo e a esfera conjugal-familiar. Assim compartimentada, a sexualidade, afora representada como domínio portador de significado em si, converte-se em referente crucial de nossa identidade. Em contraste, as classes populares subsumem sexo e prazer a uma ordem moral maior consubstanciada na família e/ou em outras redes sociais; no limite, o sexo é destituído de sua conotação propriamente sexual para afirmar-se como insumo que tonifica essa moral. ${ }^{2}$ E enquanto a relação entre gêneros em meio aos modernos funda-se nos princípios da igualdade e da indiferenciação (ver, por exemplo, Salem 1987, 1991; Heilborn 2004), vin- 
gam, entre os populares, a crença e o valor em suas inarredáveis diferenças estatutárias. Expressas no binômio dentro (feminino) x fora (masculino), tais diferenças, ao mesmo tempo que imprimem um caráter legitimamente hierárquico à relação entre gêneros, os tornam verdadeiramente complementares. Esta cosmologia encontra, assim, no princípio da reciprocidade seu esteio mais importante [cf. Duarte $(1986,1987)$; Heilborn (1999); Leal \& Boff (1996); Heilborn \& Gouveia (1999)].

Este paradigma está passando por revisões (ver, por exemplo, Duarte 2005); ainda assim, seu arcabouço central mantém-se vigoroso. É com ele que discuto. Mais precisamente, parte deste artigo dedica-se a rever duas de suas premissas centrais: a de que é na família e na localidade, muito mais do que no sexo, que se armam ambas as identidades de gênero; e a de que sua relação se funda no princípio da reciprocidade. Não pretendo esgotar essa produção; restrinjo-me aqui a uns poucos trabalhos, mas bastante representativos, desse paradigma interpretativo.

Em um trabalho anterior, focalizei as representações sobre a sexualidade masculina e a feminina, bem como a relação entre gêneros, a partir do ponto de vista dos homens de classe popular (Salem 2004). Ele tinha por base 41 depoimentos retirados do material qualitativo da Pesquisa Gravad que, em 2000, reuniu 123 entrevistas com jovens de ambos os sexos pertencentes às classes populares e médias, visando recuperar seus comportamentos sexuais e reprodutivos em uma perspectiva biográfica. ${ }^{3} \mathrm{Em}$ contraste com a tese do modo "relacional" de construção da identidade na classe popular e com a do sentido totalizante que a sexualidade retém entre eles, propus que os homens de classe popular, além de segmentarem a sexualidade, encontram nela uma referência básica de sua definição identitária. Esta conclusão pode ser contestada com base em dois argumentos. Primeiro, é possível objetar, aliás com certa justeza, que a percepção de si mesmos como submetidos a uma energia irresistível (que designei de "sexo pulsional") era instigada pelo próprio tema da pesquisa que, focando a sexualidade, incitava a colocação do sexo em discurso. Segundo, pode-se alegar que o fato de os informantes terem entre 18 e 24 anos confere à sexualidade significados específicos e talvez mais exacerbados. Porém, e em favor da minha conclusão, saliento que o mesmo roteiro de entrevista, quando aplicado aos outros segmentos sociais da mesma faixa etária, propiciou modos alternativos de apresentação de si. Ainda assim, a relevância da variável "tempo" —insistida por Leal ${ }^{4}$ —é retomada adiante. A elaboração do mencionado artigo e os depoimentos femininos resultantes da pesquisa Gravad instigam-me agora a ressaltar, e a levar a sério, os significados notavelmente distintos que homens e mulheres da classe popular imputam à sexualidade, bem como a refletir sobre as conseqüências analíticas daí derivadas. 
A sugestão de contemplar a matriz de gênero quando se alude à construção da pessoa em geral e à sexualidade em particular decerto não constitui novidade. Porém, ainda que o procedimento seja seguido pela vertente interpretativa com a qual dialogo, ela o faz, muitas vezes, especialmente no tocante à sexualidade, focalizando apenas um dos gêneros - geralmente o feminino - que passa então a funcionar como porta-voz do outro. Leal \& Boff expressam desconforto similar ao postularem que "talvez a antropologia das classes populares, quando lida com o homem fora da esfera do trabalho, tenha, em certa medida, 'feminilizado' os homens, já que as mulheres são informantes privilegiadas" (1996:133, grifo meu). Ademais, mesmo ao reconhecer que prazeres, sentidos e interdições sexuais são indiscutivelmente diversos para homens e mulheres, a literatura permanece assumindo que ambos se congregam na disposição para entranhar, senão diluir, sexo e sexualidade em uma outra ordem moral eminentemente relacional.

Discuto essa premissa e o fundamento último no qual ela se assenta: o princípio da reciprocidade entre os gêneros. Argumento que esse paradigma interpretativo extrapola aquilo que é uma vocação peculiar e restrita ao feminino não só para os homens como também, e talvez mais complicado ainda, para o próprio modelo; ou seja, parece-me haver uma homologia exagerada e indevida entre o modelo e o ethos feminino. ${ }^{5}$ Embora acatando a idéia de uma adesão de ambos os gêneros ao valor da hierarquia, pergunto se a relacionalidade, ou a reciprocidade enquanto viga mestra dessa cosmologia, é atributo simbólico pertinente a homens e a mulheres. Minha resposta negativa leva então a buscar o porquê e o como são construídas suas diferenças, e quais as implicações no plano analítico - inclusive no da formulação do modelo.

A tese de que a sexualidade se afirma para os homens de classe popular como domínio auto-referido, afora destoar da maneira como a literatura entende seu sentido no contexto holista, também os aproxima, à primeira vista, dos segmentos modernos. Essa afinidade é, contudo, aparente: da proposta de os populares segmentarem a sexualidade não decorre a conclusão de uma diluição das diferenças culturais, e nem mesmo a de uma aproximação entre eles e os individualistas. Isto porque, endossando Duarte (1987), nada indica que estes sujeitos, diversamente dos individualistas, submetam o sexo ou a si próprios às discussões psicologizadas sobre o prazer e, muito menos, sobre a sua repressão. Por outro lado, acho que merece ser revista a idéia de o sexo não configurar para eles uma instância de apreensão racional e abstrata (conforme propugnado, por exemplo, por Heilborn 1999:41). Pois se é fato que os homens de classe popular não racionalizam sobre sexualidade com base em um código "individual-psicológico-sexualista" (Duarte 1987:214), deve-se consentir terem eles concepções bastante precisas sobre as especificidades 
irredutíveis de seu sentido e modo de expressão em cada um dos gêneros. Evidências fornecidas ao longo deste artigo suportam esta suposição.

Mas a distância dos homens de classe popular vis-à-vis ao modelo individualista expressa-se, mais definitivamente, em duas representações dominantes entre eles. Primeiro, na de se perceberem e/ou de se apresentarem como governados, no domínio da sexualidade, pela natureza, ou seja, pelo "sexo pulsional" (Salem 2004). Esta perspectiva determinista e naturalista contrasta com o voluntarismo e o culturalismo abraçados de maneira típica pelos modernos. Segundo, no endosso à lógica hierárquica de gêneros, isto é, no consentimento de homens e mulheres apresentarem naturezas e vocações díspares, sendo elas que fundam e legitimam suas competências e seus domínios exclusivos. Esta visão opõe-se ao igualitarismo inextricavelmente imbricado na ideologia individualista.

Entendo essas diferenças que separam os homens de classe popular dos modernos como estruturantes de sua visão de mundo. Questiono, por isso, a força persuasiva de uma idéia corrente na literatura que, por razões de economia, designo de "hipótese da contaminação" (ou de "iluminação", dependendo do ponto de vista). Essa hipótese, que vem freqüentemente associada a uma crítica ao paradigma holismo/individualismo, propugna que a modernização da sociedade brasileira nas últimas décadas vem dissipando as fronteiras simbólicas entre esses dois universos (cf. Zaluar 1984). Mas a tese é também, por vezes, endossada pelos adeptos do modelo. Assim é que Heilborn \& Gouveia argumentam em favor de "um atravessamento parcial da cultura individualista no contexto cultural [hierárquico]" (1999:179). E ainda Leal \& Boff que, ao discriminarem os preceitos desse universo moral segundo a matriz de gênero, concluem que, enquanto o feminino é "destacadamente hierárquico na construção de seus valores", o masculino se pauta "por valores típicos do ideário individualista, tais como 'liberdade', 'igualdade', 'autonomia'"' (1996:129-130, grifo meu). Resta saber se os significados que os homens de classe popular imputam a tais termos são coincidentes com os a eles atribuídos pelos modernos. As profundas e persistentes diferenças assinaladas entre essas configurações morais me fazem suspeitar que não o são.

Minhas reservas à "hipótese de contaminação" não se assentam na crença de uma impermeabilidade da visão de mundo holista a influências externas. Antes, insisto na inadequação de interpretar quaisquer dissonâncias entre o modelo e as informações etnográficas como se fossem testemunhos da pregnância de preceitos individualistas nas classes trabalhadoras. Já propus, em outro trabalho, uma distinção entre "individuação" e "individualização", sugerindo reservar ao último termo, e apenas a ele, o indelével 
compromisso com a ideologia individualista (Salem 1987:42-43). Pretendia sublinhar, como o faço novamente agora, que ser individuado não equivale a ser individualista. Recusar a "hipótese da contaminação" coloca a questão de como elucidar a qualidade de individuação — que também reputo como estruturante do masculino nas classes populares — e de especular sobre seu impacto na relação entre gêneros.

Entretanto, também não parece razoável justificar as disparidades entre o modelo e as informações etnográficas como redutíveis a um descompasso entre Fato e Valor, como freqüentemente alegam os adeptos do paradigma. Prefiro deslocar este mal-estar para o interior do próprio modelo indagando onde fraqueja sua capacidade de persuasão. Reitero meu desconforto quanto à maneira como aí é retratada a relação entre gêneros. Concordo com Leal e Boff sobre a necessidade de "pensar na questão de gêneros não só em suas relações, mas, sobretudo, destacando-as em suas tensões" (1996:133, grifo meu), mas distancio-me delas por não entender esses incômodos como salientáveis apenas com base em "indicadores microscópicos" (1996:129). Em termos mais gerais, não creio que os autores invocados não tenham se apercebido da "tensão" entre os gêneros tal como aqui sugerida. Tanto assim que, em importantes passagens deste artigo, recorro a teses propostas por eles próprios para construir e sustentar meus argumentos. Contudo, confiro ao dilema entre gêneros um peso analítico bem mais substancial.

Este artigo divide-se em três partes: na primeira (itens II e III), em diálogo explícito com o paradigma hierárquico, argumento que uma tensão estrutural atravessa a relação entre homem e mulher nesse contexto moral, e examino como são construídas suas inclinações divergentes. Na segunda (item IV), recorro ao conceito de cismogênese complementar (Bateson) para refletir sobre como essas vocações desencontradas podem reforçar-se mutuamente, e também para especular sobre fatores internos e externos à relação entre gêneros, que mantêm esta tensão em estado contido. Por último, nas Considerações Finais (item V), recupero as implicações que as ponderações feitas ao longo do trabalho acarretam sobre o modo como o paradigma holista entende a relação entre homens e mulheres. Sumarizo nossas divergências e sugiro ainda que elas podem remeter, ao menos em parte, a formas distintas de conceber modelos teóricos.

Uma última observação: este artigo não contempla uma copiosa literatura - nacional e internacional — que, apelando para outros referenciais teóricos, também se pronuncia sobre algumas das questões aqui tratadas. Entendo que esta exclusão possa ser interpretada como limitando o alcance da interlocução deste trabalho. Contudo, ao eleger os adeptos do paradigma holista como interlocutores privilegiados, não tenho a intenção de restringir 
o debate a eles. Até porque, de certo ponto de vista, a discussão com este modelo teórico constitui porta de entrada para formular, ou realçar, uma leitura particular sobre a relação entre homens e mulheres na classe popular. E é esta leitura, tanto quanto o diálogo com o paradigma holista, que estão sendo aqui colocados para discussão.

\section{Das oposições de gênero}

A literatura salienta várias oposições contrastivas entre o feminino e o masculino no que respeita à sexualidade, as quais se expressam desde o plano mais concreto (isto é, onde está preferencialmente alocado o "prazer" de cada gênero) ao mais abstrato (ou seja, nos significados que cada um imprime a ela). Estabelece-se, em primeiro lugar, uma correspondência entre o masculino/penetração e mulheres/preliminares (ou romance). Leal \& Boff (1996:130), Heilborn (1999:44) e Torres (2002) destacam este ponto.

Tal oposição está intimamente relacionada a uma segunda. Conforme já ressaltei em trabalho supracitado, a propensão masculina para segmentar a sexualidade evidencia-se de várias maneiras. Uma delas é a sua insistente dissociação entre sexo e vínculo: o primeiro, destinado a satisfazer um impulso premente e descontrolado, é entendido (e atuado) como um fim em si mesmo (Salem 2004). ${ }^{6}$ Esta perspectiva contrasta nitidamente com a que é expressa pelas mulheres de classe popular — e os depoimentos da pesquisa Gravad são ilustrativos a respeito. Sobressaem deles dois significados básicos imputados ao sexo: ele é invariavelmente entendido como um "complemento a" (vale dizer, como englobado pelo, e submetido ao "amor")7 ou um "meio para" (ou seja, como um recurso para barganhar com o homem). A especificidade do estilo feminino é corroborada quando se considera a versão masculina nativa: a qualificação das mulheres como "mais apegadas", "mais agarradas" (e, portanto, de si próprios como "menos") e as usuais acusações de que elas "usam o sexo para prendê-los" reiteram que, também no seu entender, a sexualidade feminina está a serviço de algo para além da satisfação sexual. Em síntese, há um significativo consenso entre os acadêmicos e os nativos no que se refere à inclinação feminina para subordinar o sexo às engrenagens da relação. ${ }^{8}$

Ou, mais precisamente, das relações. Em um comentário escrito ao trabalho de Torres (1999) sobre representações e vivências sexuais entre adolescentes pobres em Salvador, destaquei uma série de oposições contrastivas de gênero. Notava, então, que o valor alocado pelas meninas ao "namoro de portão"9 era condensador do modo como elas concebiam sua 
sexualidade e/ou a relação entre gêneros: afora ensejar o compromisso do garoto com uma relação mais estável e duradoura, ele é indicativo de que, para elas, o namoro não diz respeito apenas ao casal. O par é englobado pela rede familiar, que se afirma simultaneamente como agência de controle e de legitimação da relação. Ainda no entender delas, e idealmente ao menos, o namoro deve ocorrer em lugares "claros" e socialmente aprovados (como a "Igrejinha" ou o "portão da casa"), e a "transa" propriamente dita, ademais de "calma" e precedida de preliminares, deve acontecer em um espaço íntimo e preservado. As representações dos meninos adolescentes são bem distintas: sexo para eles reduz-se ao coito, e a sedução ou namoro (referidos como formas de "tapear" as meninas ou de "levá-las no bico") afirmam-se como meios para chegar a ele. Além de "apressada e sobressaltada", a atividade sexual ocorre em lugares escuros, proibidos e perigosos (como "beco", "estaleiro" etc.). O exercício de sua sexualidade também exclui a família: os meninos não estão submetidos ao seu controle e seus relacionamentos prescindem de sua aprovação. Essas considerações revelam que a vocação masculina para desentranhar o sexo de redes e/ou de considerações morais mais abrangentes e a inclinação feminina inversa noticiam-se já na adolescência - e, entre os meninos, junto com sua iniciação sexual. ${ }^{10}$

Mas a versão feminina acerca dos homens permite ir adiante: não é só a sexualidade masculina que, por condições de sua natureza, se encontra desatrelada da família, mas também, et pour cause, eles próprios. A insistência de entrevistadas em qualificá-los como "presa fácil de mulher e [por isso] liga menos pra família", como "mais irresponsável" e "mais liberto por natureza" (Salem 1981:60) desvela a representação nativa de que os homens são "naturalmente" mais individuados do vínculo e da família.

A polaridade representacional da mulher como "mais agarrada" e do homem como "mais desapegado" conduz ao que considero ser o cerne das oposições contrastivas de gênero: o pendor feminino para $o$ vínculo x $a$ vocação masculina para circular entre mulheres. ${ }^{11}$ Postulo também que se encontra, nesta equação, uma formulação condensada da tensão estrutural entre gêneros. A "traição" masculina, quando atuada sem comprometer o vínculo e a unidade familiar, constitui o aspecto mais superficial e menos dramático dessa circulação. Não é por outro motivo que as mulheres expressam uma notável condescendência com respeito a essa prática masculina. Pode-se designá-la "circulação simultânea". ${ }^{12}$ Mas a circulação reveste-se de um significado distinto, e bem mais dramático, quando ela redunda — de modo freqüente, aliás - no abandono da parceira, da prole e/ou da unidade doméstica para a qual eles nem sempre voltam a comparecer, física ou financeiramente, ou o fazem de modo intermitente. Nessas circunstâncias, 
o homem viola em seu âmago o preceito da reciprocidade entre gêneros e, de maneira mais ou menos típica, engaja-se em alianças sucessivas e contingentes com outras parceiras ao longo da vida. É esta última modalidade de circulação, que nomeio "sucessiva", que importa aqui considerar. ${ }^{13} \mathrm{~A}$ oposição vínculo $\mathrm{x}$ circulação ecoa em outras amplamente destacadas pela literatura: à mulher estão associadas propriedades de permanência, continuidade e de sentimento, ao passo que ao homem correspondem atributos de impermanência, descontinuidade e sensação.

Inúmeros trabalhos destacam a impermanência do homem, sua "circulação sucessiva" e/ou a recorrente disrupção da reciprocidade pressuposta na relação entre gêneros. Os mais contundentes versam sobre a matrifocalidade que vigora nesses segmentos sociais, armada sobre a evidência de um grande número de unidades domésticas que sobrevive sem a presença contínua do homem ou sob a sucessão de vários deles (Barroso 1978; Salem 1981). ${ }^{14}$ Encontra-se, justamente aí, a raiz da pregnante percepção feminina acerca da precariedade dos laços conjugais. Em outras palavras, assenta-se aí o fundamento da "ambivalência em relação aos homens ou mesmo em relação ao homem, enquanto valor" (Duarte 1987:219). Ainda que casos de abandono do lar pela mulher possam ocorrer, eles dizem respeito à ordem da exceção. Aludindo à lógica entre gêneros na sociedade gaúcha, Leal \& Boff concluem que "as mulheres tentam alcançar os homens, os homens evitam esse contato" (1996:123). A partir dessa perspectiva, a evitação masculina com respeito ao vínculo, mais do que afrontar o preceito da reciprocidade entre gêneros, implode com ele por antecipação.

\section{A construção das oposições de gênero: vínculo x circulação}

Vejamos agora como se constroem as vocações de cada gênero e as propriedades simbólicas a elas associadas: de um lado, feminino/vínculo/permanência/continuidade e, de outro, masculino/circulação/impermanência/descontinuidade. Ou, para usar as categorias nativas, como se armam a qualidade feminina de "apegada" e o atributo masculino de "desgarrado".

Os autores aos quais recorro neste ponto da argumentação — os mesmos, aliás, com os quais venho dialogando até agora - elaboram sobre a socialização diferencial de gênero; mais precisamente, destacam fatores que promovem a instalação de um estilo de ser e de estar no mundo. Antecipando o examinado em seguida, salienta-se uma intensa ambivalência na constituição do masculino em contraste com uma ausência de ambigüidade significativa na moldagem do feminino vis-à-vis ao doméstico. Essa ambivalência do homem 
importa para o meu argumento, posto repercutir tanto no papel primordial que lhe é destinado quanto na relação entre gêneros no universo holista.

Senão, vejamos. Duarte sugere que implícito na categoria da obrigação - expressiva dos imperativos morais do homem com relação à família — está o preceito de sua exterioridade em relação à casa: é ele, afinal, que assume a representação externa da unidade doméstica. O autor conclui que "uma estrutura que aloca no homem um tal caráter de exterioridade para a casa e que o associa, portanto, de certo modo à vida de rua (a socialização dos meninos homens enfatiza muito claramente este ponto) comporta um potencial de ambigüidade muito alto" (1986:177, o último grifo é meu). Heilborn localiza a origem dessa "ambigüidade estrutural" [sic] em um momento preciso da vida dos meninos das classes populares: por volta dos 13 anos, precisamente quando, propõe a autora, se observa uma confluência entre o calendário de sua iniciação sexual e o de sua experiência mais regular no mercado de trabalho. Desta coincidência de datas, Heilborn conclui que "se trata de um movimento físico e moral de exteriorização em relação ao mundo da casa. Em termos estruturais é, antes, uma expulsão que o mundo da casa, nos grupos populares, realiza com seus membros masculinos" (1999:43, grifo meu). Leal \& Boff também endossam a idéia (1996:133). Em síntese, é esta expulsão que responde por sua ambigüidade estrutural em relação ao núcleo doméstico.

Esta tese contrasta nitidamente com o postulado pela "hipótese da contaminação". De acordo com a última, a individualização dos homens de classe popular é fenômeno conjuntural recente e, por isso, recorre-se a fatores externos ao modelo holista para explicar uma certa duplicidade moral no seu modo de ser. Em contraste, as reflexões acima sugerem que a individuação (já) dos meninos está inextricavelmente associada à própria elaboração do sujeito masculino. E com um preço, pois, ao mesmo tempo em que sua "expulsão" se impõe como requisito para que o homem venha a desempenhar sua "obrigação", ela introduz uma ambivalência crucial no cumprimento da mesma.

Tais considerações levam-me a concluir que hierarquia e individuação são dois atributos igualmente decisivos, e estruturalmente determinantes, na conformação do modo de ser masculino nesse contexto moral. Distancio-me aqui dos autores invocados: enquanto eles subordinam analiticamente a ambigüidade masculina com relação à casa ao princípio da reciprocidade entre gêneros, estou propondo situar ambos estes vetores em um mesmo plano de relevância analítica.

Também importante para a minha argumentação é a notável sintonia entre a "ambigüidade estrutural" masculina em relação ao doméstico e sua 
vocação à circulação, à impermanência e/ou ao "desapego". Dessa perspectiva, a compulsão masculina à circulação afirma-se como uma inclinação moral prevista, senão estipulada, pelo próprio modelo. Duarte sugere que a matrifocalidade das classes trabalhadoras "poderia ser melhor compreendida sob o ângulo dessa ambigüidade masculina" (1986:177). Contudo, o autor expele esta ambivalência do paradigma ao qualificar este e outros comportamentos correlatos dos homens de classe popular como "desviantes mesmo para eles" (idem); insiste, portanto, no argumento do divórcio entre Fato e Valor. Prefiro, ao invés, tomar esta insistente inclinação para "transgredir" como forma expressiva de que o homem nas classes populares é moldado para, simultaneamente, honrar o princípio da reciprocidade entre os gêneros, e para romper com ele. As repercussões da individuação masculina no plano da relação entre gêneros não podem, portanto, ser relegadas ao estatuto de "evidências microscópicas".

Porém, a tensão estrutural entre os gêneros não decorre apenas da duplicidade moral masculina, mas sim de sua conjugação com a maneira tão diversa de ser feminina. O homem combina, estruturalmente, o endosso ao valor da hierarquia como conformador da relação entre gêneros, no que é referendado pela mulher, mas simultaneamente não adere ao preceito da reciprocidade com a mesma intensidade manifestada por ela. Em outros termos, eles conjuminam hierarquia e individuação, ao passo que elas associam hierarquia e reciprocidade. E, de fato, também a correlação entre feminino e vínculo - e/ou a relacionalidade como atributo simbólico mais tipicamente feminino - é da ordem do constrangimento, mais do que da exceção ou da eleição. Enquanto a socialização dos homens veicula uma ambigüidade com relação ao doméstico, a das meninas refrisa seu valor: longe de sofrerem uma "expulsão" da casa, elas são nela retidas, seja por meio do controle familiar, seja porque elas continuam responsáveis pelas tarefas domésticas, mesmo quando trabalhando fora. A mulher permanece, portanto, "interna e privada, imbricando-se de maneira inextricável com o próprio sentido da casa" (Duarte 1986:177) — e pode agregar-se do vínculo, da permanência, da continuidade, da relacionalidade. Elucida-se assim sua qualidade de "apegada", e o porquê de o vínculo e o valor-família serem mais afinados ao feminino do que ao masculino..$^{15}$

Vale elaborar ainda sobre possíveis reverberações que a experiência da matrifocalidade acarreta, desde cedo, nas predisposições dos gêneros. Esta vivência familiar retrata, em termos pictográficos, a imagem de que as mulheres ficam (na casa) enquanto os homens são passageiros; ela é, por isso, fértil para a aprendizagem e a internalização do pendor feminino para a permanência, e o do masculino para a circulação. É possível ainda, no 
que tange às meninas, que a sucessão de homens que "passam" pela casa as instruam sobre a fragilidade não só dos laços conjugais como também da suposta complementaridade entre gêneros. Da perspectiva dos meninos, a vivência da matrifocalidade - precisamente por encenar, e ensinar, a impermanência do homem — é mais um alimento para a sua "ambivalência estrutural" com relação à domesticidade.

Em suma, ao invés de interpretar a tensão entre gêneros como uma decorrência de a mulher abraçar valores holistas e o homem os individualistas (Leal \& Boff 1996), prefiro entendê-la como resultante do fato de a mulher ser relacional enquanto ele é, relativamente a ela, individuado - o que, repito, não quer dizer individualista. Esta sugestão — se pertinente - impacta contra o próprio desenho da cultura hierárquica. Pois se a moral relacional coincide mais claramente com o ethos feminino, conclui-se que, mais do que "feminilizando os homens" (Leal \& Boff 1996), a antropologia das classes populares, ao tratar da relação entre gêneros, feminiliza o próprio modelo hierárquico. É como se, tal como ocorre no domínio da família, também fosse conferida à mulher a função de zelar pela reprodução e pela manutenção moral da cultura e do modelo holistas.

A postulação do caráter estruturalmente sedimentado da impermanência masculina (e da permanência feminina) também conduz a admitir que a tensão entre gêneros não constitui fenômeno recente. Percebo a individuação dos homens de classe popular como lógica e factualmente anterior à sua eventual "contaminação" pelos valores individualistas modernos. Mesmo aventando que o "desencontro" entre homens e mulheres da classe popular possa ter se intensificado nas últimas décadas, enfatizo o seu caráter crônico, enraizado e estrutural. Entender, como estou propondo, o binômio vínculo $\mathrm{x}$ circulação como constitutivo do sistema implica reconhecer que, mais do que funcionalmente integrada, a relação entre os gêneros comporta um engasgo estrutural nesse contexto moral.

De certo ponto de vista, a polaridade vínculo x circulação constitui derivação de uma outra muito destacada pela literatura: interioridade feminina x exterioridade masculina ou, abreviadamente, "dentro x fora". Essas oposições, contudo, detêm estatutos bastante diversos: a última é a expressão máxima da reciprocidade entre os gêneros nesse contexto moral; nela, os pólos apresentam-se como compatíveis e complementares e eles se soldam, precisamente, graças às diferenças estatutárias. As eventuais falências desse arranjo não são constitutivas desta oposição. Diverso é o caráter da equação vínculo x circulação: aqui o feminino e o masculino despontam não só como diferentes em seu conteúdo, mas sobretudo como divergentes em sua direção. Ela é o reverso do princípio da reciprocidade e, por isso, eu a 
entendo como uma enunciação sintética da tensão estrutural entre gêneros. $\mathrm{E}$, da mesma forma que propus que a individuação masculina não deva ser lida como subordinada à sua vocação para a hierarquia, argumento que a oposição vínculo $x$ circulação não merece ser interpretada como uma dissonância entre Fato e Valor. Antes, ela deve ser entendida como convivendo de modo tenso com a equação dentro $\mathrm{x}$ fora - ou seja, com o preceito da reciprocidade - em um mesmo plano de relevância analítica.

Mas voltemos ao tema da "expulsão" masculina do espaço doméstico. Há indicações na literatura de que ela persiste perseguindo o homem para além da adolescência - momento, como vimos, crucial na afirmação do fenômeno. Elegendo informantes de 40 a 60 anos, Leal \& Boff (1996) examinam as "queixas" dos homens que circulam. As autoras salientam que, nos casos em que sua impermanência é responsável pela dissolução conjugal, estabelece-se, como um mecanismo reativo, uma aliança entre mães e filhos que redunda em uma "expulsão" [sic] dos homens circulantes. As autoras propõem o elo seguinte dessa cadeia: "o homem 'expulso de casa' torna-se, no seu próprio discurso, o pai-marido abandonado, injustiçado, e assim estende o convite para outra mulher, mais digna, corrigir a situação" (1996:127). Infere-se daí que os homens tendem a compensar sua eventual exclusão da rede de solidariedade fundada na filiação com mais circulação. No limite, esse circuito só será interrompido quando o homem, rompendo com o padrão de impermanência, tornar-se (femininamente) mais permanente - justamente, aliás, quando está mais velho. Nota-se aí um exemplo de como a variável tempo pode produzir inflexões significativas nas vocações de gênero.

Postula-se, às vezes, que as propriedades simbólicas relativas aos gêneros transbordam suas inserções sociais particulares. Este é, por exemplo, o argumento que perpassa "Gênero e Hierarquia. A Costela de Adão Revisitada" (Heilborn 1993; ver também Heilborn 2004). O artigo, no qual a conjugalidade heterossexual é comparada às homossexuais (nas suas variantes gay e lésbica) em um universo de camadas médias, parece dispor-se a especular se uma força cultural de intensidade igual, senão maior, é capaz de contrabalançar, ou desorganizar, a articulação entre masculino, marcação, impermanência, descontinuidade, e feminino, não-marcação, permanência, continuidade. ${ }^{16}$ A autora é cética a respeito: ela insiste que a adesão desses estratos à ideologia igualitária não é suficiente para anular a lógica distintiva de gênero, que permanece atuante nas três modalidades de casal. Heilborn entende esta persistência como evidência da inevitabilidade da lógica hierárquica na classificação de gêneros. Se bem que eu não esteja aqui imbuída de propósitos comparativos, arrisco a hipótese de que a operação desse princípio lógico, 
mesmo que universal, encontra sua mais perfeita tradução entre homens e mulheres de classe popular. Estes sujeitos encarnam, desse ponto de vista, exagerações das propriedades simbólicas do masculino e do feminino em relação aos modernos, graças, de um lado, a valores que embasam sua cosmologia e, de outro, a condicionantes de classe.

Comecemos pelo caso dos homens. Sugiro que seu explícito reconhecimento da hierarquia conformando a relação entre homem e mulher, e também a modalidade de sua socialização — não sendo amaciados pelo igualitarismo — evidenciam, de modo mais contundente, a lógica distintiva de gênero. Não surpreende, aliás, que esses sujeitos atribuam sua circulação à sua própria "natureza". O pendor masculino para a impermanência é ainda mais radicalizado por sua inserção de classe. Enveredando por um plano mais concreto de análise, é pertinente sugerir que as pressões para que o homem de classe popular cumpra o papel de provedor são tão intensas e tão difíceis de serem atendidas - sobretudo em um contexto onde grassam salários miseráveis e o desemprego - que elas acabam, paradoxalmente talvez, por incitá-lo a evitar e/ou a se desvencilhar de vínculos mais permanentes. A ferida na auto-imagem masculina, imposta pelas condições de classe, seria assim mais um fator, dentre outros já arrolados, que nutre sua "ambigüidade estrutural" com relação ao doméstico. ${ }^{17}$ É possível ademais que, diante de seu "fracasso" como trabalhador e provedor, ele seja instigado, como uma espécie de mecanismo compensatório, a estabelecer uma equivalência entre a masculinidade e a virilidade propriamente física; a sexualidade seria, assim, o lugar simbólico de afirmação de sua masculinidade. A apresentação de si mesmo como "possuído" pelo sexo; a circulação entre várias parceiras (simultâneas ou sucessivas); o "fazer" filhos etc. reafirmariam, a partir dessa perspectiva, a identidade masculina. Também o apego das mulheres ao vínculo e o valor que elas imputam à hierarquia de gêneros encontram-se aguçados pelas condições de vida dessas populações: é como se, para fazer frente a elas, as mulheres "precisassem" do homem em um sentido mais radical. Retomo esta questão adiante.

\section{A cismogênese complementar e a radicalização das vocações de gênero}

Ao lado do valor-hierarquia e dos condicionantes de classe, um outro fator que pode elucidar a radicalização do contraste entre as predisposições femininas e masculinas remete à cismogênese complementar, tal como proposta por Bateson (1958). Partindo da relação entre homens e mulheres na sociedade 
Iatmul, o autor sugere que as diferenças entre os "ethos dos sexos", além de produzidas graças às suas socializações diferenciais, podem também ser aguçadas graças à dinâmica cismogênica. O conceito é importante aqui, porquanto estabelece uma articulação entre as disposições simbólicas de cada gênero no sentido de seu reforço mútuo; ele fornece, em outras palavras, uma abordagem genuinamente relacional para o entendimento de sua dinâmica, bem como de suas tensões. Dedico-lhe, por isso, um tópico especial.

O processo de cismogênese tem sua singularidade no fato de desenvolver-se por reações e alimentações mútuas: a ação de A desencadeia uma resposta em B que, por sua vez, desencadeia uma reação ainda mais radical de A, e assim sucessivamente. Bateson estipula, no que tange aos gêneros, que essa dinâmica pode resultar em uma diferenciação progressiva e exagerada de seus ethos particulares, acentuando o contraste em direção à polarização. Nessas situações, as disposições de cada gênero sofrem uma "distorção": a acentuação de suas especializações em uma só direção conjumina-se com o subdesenvolvimento dos outros aspectos, que passam a ser considerados como exclusivos ao outro gênero. Uma das conseqüências dessa dinâmica - diz o autor - é que quanto mais aguçado for o contraste entre o feminino e o masculino, e suas respectivas especializações, mais difícil será para cada um deles entender o ponto de vista e as reações emocionais do outro. Ainda de acordo com Bateson, é inerente à própria natureza da dinâmica cismogênica escalar indefinidamente, implicando, no limite, e se não contra-arrestada, a destruição do sistema; isto é, da própria relação.

A cismogênese complementar prevê para se instalar uma relação fundada em diferenças ${ }^{18}$; portanto, o conceito é adequado para pensar a relação entre homens e mulheres na classe popular. De fato, o valor que ambos os gêneros imputam à hierarquia pressupõe - e ao menos no plano do modelo não sobrevive sem - uma demarcação rígida entre o feminino e o masculino. ${ }^{19}$

Parece-me, porém, e distanciando-me de Bateson, que nem toda a radicalização das especialidades de gênero, mesmo quando intensa, coloca em risco a relação. Para fundamentar o argumento, retomo o contraste entre as peculiaridades que separam a polaridade "dentro/fora" daquela "vínculo/circulação". Na primeira, as diferenças entre os pólos opositivos - expressivas de sua conformação hierárquica - não ameaçam nenhum sistema; pelo contrário, são seu fundamento último. A segregação radical entre o feminino e o masculino, longe de introduzir uma complicação no sistema, anuncia-se como valor; assim sendo, ela só é grave quando vista e avaliada por uma lógica estranha a esse contexto ético - leia-se, pela lógica igualitária. ${ }^{20} \mathrm{Já}$ vínculo x circulação fala, ao contrário, de propensões de gênero que reportam 
a um "desencontro": suas direções são tão irreconciliáveis que, no limite, a própria idéia de "troca" perde significado. Em outras palavras, a permanência feminina descansa na categoria masculina de exterioridade ou de "obrigação", mas não pode, por definição, apoiar-se na de impermanência.

Centro-me aqui, portanto, na equação vínculo x circulação por ser ela, e só ela, potencialmente destrutiva do sistema moral fundado na reciprocação. E pergunto, em primeiro lugar, se ela pode ser lida à luz do conceito de cismogênese complementar, ou seja, se a própria dinâmica da relação entre gêneros pode reforçar essas vocações desencontradas. Mas pelo fato de eu não estar argumentando por uma falência desta relação, e sim por uma tensão endêmica a ela, decorre uma segunda questão, qual seja, especular sobre a persistência do valor-família, ou do "homem como valor" em um contexto no qual a impermanência masculina coloca reiteradamente em questão o preceito da reciprocidade. Já foram salientados acima fatores que não só instalam como eventualmente reforçam o pendor masculino para a circulação e o feminino para a permanência. Suas socializações particulares; a experiência desde a infância com a matrifocalidade; a especificidade de seu contexto moral e as determinações mais diretamente relacionadas à sua inserção social ensinam a cada gênero não apenas a sua própria inclinação, mas também as do(a) outro(a). Cabe agora perguntar se, e como, é possível que suas respectivas disposições para a permanência e para a impermanência entrem em uma dinâmica tal a ponto de se alimentarem mutuamente em direção à polarização.

Não é de todo improvável que a representação e a vivência (direta ou vicária) de que o homem "escapa" ao vínculo radicalize ainda mais tanto a obsessão feminina com a aliança quanto a premência de "prendê-lo". Recorrendo a informações etnográficas, sabe-se que a mulher atua nesta direção acionando recursos que vão desde as crises de ciúmes (que os homens abominam) até aqueles reputados como escusos - o que eles próprios e a literatura pertinente referem-se como o "uso" do sexo e sobretudo da gravidez. Esta resposta feminina, ao mesmo tempo que fomenta a percepção masculina de ser a mulher dissimulada e/ou maquiavélica (Salem 2004:5758), agrava no homem a sensação de que ela visa apenas enredá-lo nas teias do vínculo. Esta acusação, vale notar, é muitas vezes acionada por ele - inclusive contra parceiras consideradas "fixas" - a posteriori, isto é, depois de o vínculo ter sido desfeito. ${ }^{21}$ Ele tenderá a esquivar-se da relação e, mesmo eventualmente, das responsabilidades com relação à criança; e as condições de classe, conforme já aventado, podem estimular, paradoxalmente talvez, mais ainda essa propensão. Também não deve ser menosprezada a possibilidade de que, em parte ao menos, o homem se sinta "liberado" com 
relação à prole por saber que, de um modo ou de outro, sua parceira e/ou familiares se responsabilizarão por ela. Desse ponto de vista, a impermanência masculina descansa na permanência feminina e/ou na de sua rede de apoio, ou seja, estes agentes, justo porque "permanentes", são quem, de uma perspectiva bastante particular, "autorizam" a circulação do homem. Esta impermanência (re)confirma a idéia mais ou menos consensual entre as mulheres de que "homem não presta" e/ou que é "irresponsável", potencializando talvez o ímpeto de retê-lo. E o homem responde... Em suma, essa espiral mutuamente agravante alimenta as estereotipias de gênero, coloca em risco o princípio da reciprocidade e introduz ainda, na relação entre homens e mulheres, um engasgo básico. Como se vê, o conceito de Bateson reconhece que a vocação feminina para o vínculo e a masculina para a circulação formam sistema.

As observações acima conduzem à segunda questão: indagar sobre os mecanismos que atuam no sentido de refrear essa espiral progressiva impedindo que o sistema redunde, no limite, em uma total falência. E, de fato, a persistente articulação entre o feminino e o vínculo é testemunho da consistência do valor-família e do homem enquanto "valor", capazes de resistir às mais insistentes frustrações. É precisamente esta resistência que faz supor que a tensão estrutural entre os gêneros encontra-se contida graças a alguns fatores. Resta cogitar sobre quais são eles.

Bateson também se pergunta sobre as condições que inibem a escalada do processo cismogênico em direção ao colapso do sistema. ${ }^{22}$ Nas páginas que abrem o capítulo, o autor postula ser inerente à natureza desta dinâmica escalar indefinidamente, colocando em risco a própria relação. Mais adiante, entretanto, ele pondera que este círculo vicioso pode se autoconter, ser contido por um elemento externo à relação ou, ainda, não ser nem mesmo interrompido e, ainda assim, o sistema se manter. Em todas essas circunstâncias, atinge-se o "equilíbrio dinâmico", ou seja, chega-se a um estado no qual as tendências para a cismogênese e/ou para a implosão final do sistema são adequadamente sustadas por processos inversos (Bateson 1958:186). O autor propõe que, ao abordar esses mecanismos de contenção, deve-se atentar tanto para fatores internos à própria relação quanto para os externos a ela. Sigo sua sugestão.

A dependência mútua que se estabelece entre homens e mulheres da classe popular desponta como razão crucial para manter o sistema em estado de "equilíbrio dinâmico". Com efeito, o valor que ambos conferem à hierarquia entre gêneros - com sua inextricável segregação entre os domínios femininos e masculinos - associado às suas condições sociais de existência, resulta em uma situação de intensa interdependência entre eles. Em um 
trabalho anterior sobre a relação entre gêneros na classe popular segundo a perspectiva feminina, eu já salientava esse ponto: "a ausência do homem é, em termos de subsistência material da unidade doméstica, especialmente dramática nesses estratos, não apenas por ser ele visto como mais capacitado para o exercício dessa função, mas também porque as condições miseráveis dessa população estimulam a mútua dependência que vincula os membros da unidade doméstica. Não é por outra razão que a experiência dessas mulheres como chefes de família é sempre citada como o momento mais doloroso de sua vida. Em face de tal situação, elas arcam sozinhas com o acúmulo e o reforço mútuo das determinações, e indeterminações, que recaem sobre sua classe e seu gênero. Talvez exatamente por isso as sucessivas experiências de abandono acabem [...] apenas lhes confirmando a crença em sua baixa capacidade para operar em território masculino, reiterando, paralelamente, a suposição de que lhes faltou o 'homem certo'" (Salem 1981:96-97). Mesmo admitindo que a imprescindibilidade do "outro" pareça mais pregnante entre as mulheres (ou, ao menos, que são elas que a explicitam mais claramente), os homens não estão isentos dela: o próprio fato de eles se engajarem, ainda que transitória e sucessivamente, com diferentes parceiras ao longo da vida, reatesta a dependência entre gêneros (e, como já sugeri, o valor que o vínculo, ainda que provisório, tem para eles).

Em suma, é como se a conformação hierárquica entre os gêneros — condensada no vigor da oposição dentro x fora - contrabalançasse a tendência cismogênica implicada em suas vocações desencontradas, expressas na polaridade vínculo x circulação. ${ }^{23}$ Mas, vale frisar, não há, do ponto de vista masculino, nenhuma incompatibilidade entre impermanência e dependência com relação às mulheres. Até pelo contrário: eles são capazes de "resolver" essa dependência com (mais) circulação, ou seja, a impermanência masculina pode persistir apesar da mútua dependência.

A contenção da dinâmica cismogênica é também esclarecida por meio de um deslocamento do nível da análise, isto é, retirando a oposição vínculo x circulação do plano estrutural e sobressaindo seu modo de atualização em níveis menos abstratos. A contemplação do plano mais propriamente etnográfico introduz qualificações, bem como suaviza a dicotomia considerada: alude-se aqui a uma predominância, e não a uma exclusividade, de inclinações de cada gênero. O descompasso estrutural entre homens e mulheres obviamente não obstrui o cumprimento da reciprocidade nem impede que o homem "permaneça" - com ou sem circulação simultânea. Da mesma forma que elas acreditam que a predisposição masculina para romper com o pacto entre gêneros pode ser neutralizada pelo encontro do "homem certo", também eles destacam que nem todas as parceiras "perturbam" - ou, ao 
menos, não o fazem no mesmo grau - e que nem todas "usam" os homens e manipulam sua sexualidade (cf. Salem 2004). Tanto assim que a perspectiva dos nativos oscila entre a generalização de que "todos os homens" e "todas as mulheres" são iguais" e o reconhecimento de que há exceções em cada grupamento. Pode-se ainda especular que cada paragem, ou intervalo, da circulação masculina nutre as mulheres com a esperança do Vínculo. Em síntese, são precisamente as inevitáveis inconsistências nos ethos de cada gênero que impelem à busca e fomentam a fé de encontrar o(a) parceiro(a) adequado(a). Reafirmando o valor-família, elas amortizam igualmente a tendência do sistema em direção ao colapso total.

Deve-se, por último, também atentar que a persistência do valor-família conta com o concurso de fatores que extrapolam a relação dos parceiros. Centrar atenção exclusiva na díade implica incorrer em um viés individualista-igualitário, já que é neste contexto ético que o casal é concebido como fazendo sentido em si mesmo. ${ }^{24}$ É possível que, em contraste, a propalada reciprocidade como pilar moral das classes populares não se aloque nem única nem talvez primordialmente no casal. Pode ir-se além, sugerindo que um dos fatores que contêm a escalada da cismogênese entre os parceiros consiste precisamente nos deslocamentos ou na difusão da reciprocidade para além de sua expressão na conjugalidade.

Nas ilações que se seguem não faço referência à reciprocidade atuada entre a parentela mais ampla. ${ }^{25}$ Centro-me, antes, em uma díade específica sobre a qual já trabalhei em artigo supracitado: a formada pela mãe e seus filhos-homens, em particular o primogênito (cf. Salem 1981). ${ }^{26}$ Este personagem, que designei de "filho-eleito", atesta uma transferência para a figura do filho do amparo masculino antes atribuído aos parceiros. O procedimento é especialmente perceptível entre mulheres que experimentaram sucessivos abandonos dos companheiros; ele expressa, assim, a expectativa de uma reparação a ser cumprida por um homem por causa da infração de outro(s). Essa transferência confirma, e perpetua, o valor conferido à complementaridade entre o masculino e o feminino, bem como a feição hierárquica que a informa: o filho-homem, encarado como representante da unidade familiar no mundo externo, é quem possibilita a permanência da mãe no interno. Reestabelece-se, portanto, nessa díade o vigor da oposição dentro x fora, com uma vantagem: precisamente porque assentada na consangüinidade, essa relação é investida pelas mulheres da esperança em uma solidez que se contrapõe à incerteza que caracteriza a estabelecida com o parceiro. Segundo uma de minhas informantes: "amor de filho nunca acaba, e amor de homem é sempre passageiro" (Salem 1981:89). É como se a impermanência do companheiro fosse compensada pela permanência, quase feminina, 
de seu filho-eleito. Em suma, este personagem, e/ou a relação que a mãe estabelece com ele, não só reitera o valor-família como também amortiza a "ambivalência em relação aos homens ou mesmo ao homem enquanto valor" (Duarte 1987:219).

Os depoimentos dos jovens rapazes da pesquisa Gravad oferecem, ainda que de modo tímido e insuficiente, evidências que permitem fechar o circuito das lealdades intergeracionais salientando, agora, a ótica do filho. Alguns deles manifestam, de modo inteiramente espontâneo, um intenso reconhecimento para com suas mães, e um forte anseio de retribuírem sua dedicação. Isso é sobretudo patente quando falta (ou faltou) a elas o apoio de um parceiro, o que reitera que a vivência da matrifocalidade constitui um adicional no compromisso moral do filho para com sua mãe.

Porém, mais do que lealdade, insinua-se em algumas entrevistas um conflito de lealdades - possivelmente radicalizado pela escassez de recursos — entre a família de origem (representada sobretudo pela mãe, mas também eventualmente pelos irmãos menores) e a de constituição. Não é incomum esses homens admitirem que comparecem mais no sustento da família original do que no de suas parceiras e filhos, sobretudo nos casos em que estes vivem com a parentela da mulher - reiterando, assim, a idéia de que a impermanência masculina descansa na permanência feminina e/ou na rede de apoio a ela. Aliás, este tipo de arranjo domiciliar — não infreqüente, diga-se de passagem - no qual os homens transitam entre a casa de sua mãe e a da parceira, se bem que justificado por razões econômicas e/ou como forma de preservar a "liberdade", não deve ser menosprezado enquanto indício dessa divisão masculina (ou, também, de sua resistência ao vínculo). Em termos mais radicais: é possível que esta "dupla moradia" seja expressiva de uma predominância valorativa imputada à família de origem relativamente à de constituição. Este conflito de lealdades entre duas mulheres ou dois grupos domésticos manifesta-se ainda por outras vias mais sutis. ${ }^{27}$ Há, por exemplo, o caso de um informante que, embora se declarando "casado" e com filho, justificava estar procurando trabalho fixo porque "tenho que ajudar minha mãe", com quem morava. Ou ainda aquele que afirmava querer ter um filho porque "sou doido pra dar um neto pra minha mãe". Ou um outro que, coabitando com sua mãe e uma filha de uma relação anterior, ressaltava o intenso apego entre elas para justificar sua reticência em casar com a namorada com a qual se relacionava há dois anos: "não quero destruir a vida da minha mãe, porque ela é muito apegada na menina". ${ }^{28}$

Duarte sugere que a condição masculina de "respeitabilidade" envolve "o seu desempenho global como trabalhador, como filho, como marido, como pai" (1986:176). Mas apoiando-me nas evidências acima, e também na 
tese da circulação masculina, pergunto se estes papéis estariam revestidos de igual valor para o homem. Pois se o sistema individualista funda-se na indiferenciação e na horizontalização das relações sociais (Heilborn 1993), seu contraponto modelar - o sistema hierárquico - pode, senão deve, estar ancorado em uma diferenciação e em uma verticalização das relações, incluindo-se aí as familiares. Estou, em suma, propondo a título de hipótese que o papel de marido/parceiro nas classes populares pode estar legitimamente subordinado ao de filho, da mesma forma que a figura da mãe pode prevalecer sobre a da parceira.

Não me sinto confortável para avançar muito sobre o papel de pai nessa hierarquia de relações. É possível que nos casos em que ele "assume" a criança, o valor da prole também prepondere sobre o da parceira, mas não me arrisco a especular sobre o posto das crianças relativamente ao da avó (ou seja, à mãe do informante). É patente, contudo, que inúmeros entrevistados da pesquisa Gravad experimentaram a ausência da figura paterna, redundando, em alguns casos, no que pode ser designado de uma (comovente, aliás) "estratégia de reparação": atribuindo os problemas que atravessaram na infância e na adolescência a esta ausência, eles declaravam a intenção de não repetirem com seus filhos o mesmo modelo de relação (ou de falta de relação). Em muitos outros casos, entretanto, a atitude dos informantes em relação à prole reproduzia o modelo familiar por eles vivido. Tomando por base sugestões acima feitas, poder-se-ia projetar que, particularmente nos últimos casos, o fato de os filhos dos entrevistados estarem vivendo em famílias matrifocais (efetivas ou virtuais) converte-os em candidatos potenciais ao posto de "filhos-eleitos" por suas mães. E/ou ainda, lembrando a hipótese de Leal \& Boff, esta prole estaria, como uma reação a tal experiência familiar, inclinando-se para formar com a mãe uma aliança da qual o pai (circulante ou ausente) estaria excluído.

A força da díade mãe-filho(s), mesmo que aqui enunciada a título de hipótese, imporia introduzir qualificações na conclusão já sugerida de que enquanto as mulheres conjuminam hierarquia e vínculo, os homens associam hierarquia e individuação. Com efeito, talvez seja mais pertinente caracterizar os homens de classe popular como simultaneamente hierárquicos e individuados na relação com as parceiras-eleitas, e como hierárquicos e relacionais com respeito às mães. ${ }^{29}$ Pode-se arriscar ainda mais: tentando estabelecer uma relação entre os modos como o homem se relaciona com essas personagens femininas, dir-se-ia que os homens de classe popular são individuados com respeito às parceiras justamente porque são pouco individuados com relação às suas mães. No limite, portanto, é como se a centralidade da mãe, ou o excesso de retenção simbólica do homem no 
domínio doméstico original ${ }_{1}^{30}$ fosse mais um dos fatores que instigam sua impermanência vis-à-vis às parceiras e/ou sua resistência ao vínculo.

Mesmo sem levar o raciocínio a ilações tão extremas, pode-se concluir que a relação mãe-filho(s) nas classes populares constitui um fragmento ou serve como evidência de uma tendência mais geral: a disrupção da reciprocidade no plano da conjugalidade é estruturalmente compensada por outros pactos para além dela. E, ainda, que esses pactos alternativos são cruciais para a manutenção do valor-família e para a reiteração do preceito da reciprocidade a despeito do que ocorre entre os parceiros. É claro que pode haver infração da reciprocidade na relação mãe-filhos, mas talvez, aqui sim, se possa tributá-la a um descompasso entre Fato e Valor e/ou a pressões de ordem conjuntural.

\section{Considerações finais}

Um dos argumentos deste texto é que há uma tensão estrutural entre gêneros na classe popular, e que ela encontra expressão, exemplar e condensada, na oposição vínculo x circulação. Este dilema ancora-se, em outras palavras, no fato de que enquanto a mulher associa hierarquia e vínculo, o homem reúne hierarquia e individuação. Resulta daí a "duplicidade moral" masculina com relação ao doméstico e sua disposição à impermanência conjugal. Tão importante quanto a idéia de a reciprocidade não ser qualidade unívoca para os gêneros, é a consideração de que suas inclinações morais desencontradas e/ou a ambivalência masculina são estipuladas pelo próprio modelo.

Tais especulações - se pertinentes - têm implicações analíticas significativas sobre o paradigma holista. Primeiro, ao segmentarem hierarquia e relacionalidade, os homens de classe popular afrontam, afora o pacto entre gêneros, o próprio modelo holista que entende essas qualidades morais como indissociáveis. Ou, inversamente, mais uma vez observa-se aqui uma homologia (a meu ver, complicada) entre esse paradigma interpretativo e o ethos feminino. Segundo, da mesma forma que propus que a individuação e a ambivalência masculinas não devem ser lidas como subordinadas à sua vocação para a hierarquia, argumento também que a oposição vínculo $\mathrm{x}$ circulação merece ser interpretada como convivendo, de modo conflituoso, com a equação interioridade feminina $\mathrm{x}$ exterioridade masculina em um mesmo plano de relevância analítica. Em outras palavras, do mesmo modo que a "ambigüidade estrutural" masculina é a face malévola de sua socialização para ser o provedor, também a oposição vínculo x circulação constitui derivação perversa da equação dentro x fora. Mas ambas estas "perversi- 
dades" - insisto - merecem ser qualificadas como vetores estruturantes, respectivamente, da fabricação do masculino e da relação entre gêneros nas classes populares. Precisamente por estas razões, parece impertinente interpretar o desencontro entre homem e mulher, e/ou as repercussões da impermanência masculina no plano da relação entre gêneros, como "detalhes" etnográficos.

Não é objetivo deste trabalho antecipar o nível de comprometimento que as considerações aqui feitas implicam para o paradigma holista, e muito menos tentar resolver os problemas que elas possam eventualmente impor. Contudo, é possível que, pelo menos em parte, estejamos discutindo aqui concepções concorrentes de modelo. Mais do que redutíveis a níveis distintos de abstração, estas diferentes perspectivas parecem debater, em última instância, a questão de os modelos poderem e/ou deverem comportar em si tensões, dilemas, contradições e similares. Em contraposição a uma lógica mais formalista, creio ser possível, senão necessário, contemplar esses tipos de "dilemas" na própria formulação de modelos ou dos princípios estruturantes nos quais eles se assentam. ${ }^{31}$

Ou ainda, e meramente a título de ilustração, talvez seja possível lidar com a "duplicidade moral masculina" — e até mesmo com a convivência tensa entre vínculo x circulação, de um lado, e dentro x fora, de outro - não como o encontro de tendências opostas e contraditórias (e que por isso no plano do modelo mereceriam ser "resolvidas" e hierarquizadas), mas como constituindo "uma coisa só". Em termos mais gerais, estou especulando sobre a possibilidade de tratar as "tendências opostas" implicadas em noções como ambigüidade, contradição, paradoxo etc. como compondo uma unidade. A questão, como se vê, é bem complexa porque, em última instância, implica transpor o próprio dualismo com o qual estamos acostumados a pensar a vida social. ${ }^{32}$ Certamente não foi essa a pretensão deste texto, e nem sei se teria competência para fazê-lo. Ainda assim, fica aberta a discussão.

Recebido em 10 de janeiro de 2006

Aprovado em 04 de abril de 2006

Tania Salem é doutora em antropologia social pelo Programa de Pós-Graduação em Antropologia Social (PPGAS) do Museu Nacional/UFRJ. E-mail: <TSalem1428@ aol.com> 


\section{Notas}

· Agradeço a Mariza Peirano pelos comentários à versão prévia deste trabalho. E também aos interlocutores (e amigos) de sempre: Luiz Fernando Dias Duarte, Maria Luiza Heilborn e Isabel Ribeiro de Oliveira.

${ }^{1}$ Esse paradigma consolida-se com a publicação, em 1986, da tese de doutoramento de Duarte sobre as classes trabalhadoras urbanas. Este marco corresponde, assim, ao que A Utopia Urbana de Gilberto Velho (1973) cumpre para o estudo de camadas médias (ver, sobre o último ponto, Salem 1985).

${ }^{2}$ Referindo-se às suas informantes, pondera Heilborn: "a própria sexualidade não é objeto de inquietação; o interesse é compreender atitudes e desejos dos companheiros. O conhecimento (reivindicado) sobre [os sentimentos e prazeres] masculinos representa um quesito do papel feminino nessa ordenação conjugal, integrando as obrigações na família" (1999:53).

${ }^{3}$ O projeto "Gravidez na Adolescência: Estudo Multicêntrico sobre Jovens, Sexualidade e Reprodução no Brasil" (Pesquisa Gravad) teve como principais coordenadores Maria Luiza Heilborn (coordenação nacional), Michel Bozon (INED), Estela Aquino e Daniela Knauth, 1999-2002.

${ }^{4}$ Cf. "Debate: Sexualidade e ciências sociais: perspectivas e paradigmas no final do milênio", reproduzido em Heilborn (1999).

${ }^{5}$ Este é, por exemplo, o caso do estimulante artigo de Duarte de 1987. Se bem que apoiado integralmente em depoimentos de mulheres, e embora lamentando não examinar as representações masculinas correspondentes, suas conclusões sobre sexo e moralidade são generalizadas para as classes trabalhadoras como um todo. $\mathrm{Ou}$ ainda, apesar das constantes alusões das mulheres à infração masculina com respeito à reciprocidade (sempre, aliás, devidamente ressaltadas pelo autor), ainda assim a relação entre gêneros, bem como o modelo, são apresentados como fundados nesse princípio moral. Em outros escritos, Duarte justifica analiticamente essas transgressões, aludindo a um descompasso entre Fato e Valor (cf. adiante).

${ }^{6}$ Pode-se argumentar — e aqui em favor do paradigma com o qual dialogo — que o divórcio entre sexo e vínculo constitui, de outro prisma, mecanismo por meio do qual os homens de classe popular preservam o vínculo - o que reiteraria o valor que esses sujeitos imputam a ele. Outras evidências fornecidas adiante me levam a preferir uma interpretação menos "colada" no modelo. Ainda assim, retomo, abaixo, o tema do valor do vínculo para os homens.

${ }^{7}$ Nas palavras de Heilborn, "é como se para [as mulheres] o amor validasse o sexo" (1999:51). 
${ }^{8}$ A idéia corrente de que as mulheres "usam" (ou "instrumentalizam") o sexo tem como parâmetro as regras de operação da sexualidade masculina. É da representação do sexo como redutível à satisfação de uma necessidade sexual que decorre a "ilegitimidade" de "usá-lo" para outros fins. Diversa é a leitura (feminina) ancorada na lógica da reciprocidade: ser moeda de troca não é extrínseco, mas intrínseco ao sexo.

${ }^{9}$ As expressões aspeadas referem-se a categorias nativas retiradas da etnografia de Torres.

${ }^{10}$ A evidência maior de que os meninos conhecem bem, e acatam, a especificidade da linguagem feminina, revela-se no fato de eles recorrerem a ela no jogo de sedução ("quero namorar na porta", "vou dar um bom futuro para você"). Porém, nota-se uma inflexão no tom da relação uma vez que entra em cena a "transa" propriamente dita, ou seja, o momento da sedução é informado pela linguagem feminina, ao passo que a "transa" - onde e como ela se processa — pela masculina.

${ }^{11}$ A idéia de circulação masculina, tal como aqui proposta, está mais próxima da de impermanência do que de uma inversão da fórmula lévi-straussiana acerca da troca de mulheres como fundamento da organização social.

${ }^{12}$ Não se devem menosprezar - e aqui novamente em favor da corrente interpretativa em pauta - indícios que atestam o "respeito" que o homem de classe popular deve às suas parceiras consideradas "fixas". A "traição" não-ostensiva e atuada de modo a, ao menos em princípio, não afetar a unidade doméstica constitui uma dessas evidências (cf. Salem 2004).

${ }^{13}$ Esta modalidade de circulação pode equivaler a sucessivos vínculos provisórios. Ao mesmo tempo em que (re)confirma a especificidade masculina (é a qualidade de passageiro que singulariza o significado do vínculo para o homem), a expressão é sugestiva do valor que o vínculo, mesmo que provisório, tem para ele. Retomo a última questão adiante.

${ }^{14}$ A matrifocalidade vem impondo-se também, especialmente nas últimas décadas, nos estratos médios. Contudo, e entre outras diferenças importantes relativas às classes populares, o valor que os modernos atribuem à "liberdade", à "autenticidade de sentimentos", à "autonomia" etc. faz com que os eventuais rompimentos da reciprocidade entre gêneros não criem embaraços para o modelo individualista, pelo contrário, são explicados por ele. Diverso é seu impacto sobre as premissas que fundam o paradigma holista.

${ }^{15}$ Encontra-se também provavelmente aí a justificativa para o fato de a autodefinição da mulher tender a ser mediatizada pela figura do outro (cf. Salem 1981; Leal \& Boff 1996:131).

${ }^{16}$ A oposição marcação (masculina) x não-marcação (feminina) inspira-se nos escritos de Marika Moisseeff. Destaco também que, embora Heilborn não inclua o par vínculo/circulação no rol das qualidades estruturais de gênero, chama a atenção 
sua interpretação de que o casal de homens é, dentre as modalidades examinadas, o que manifesta maior probabilidade de implosão e, inversamente, a de que o lésbico é o que apresenta a maior estabilidade relativa. Acatando sua sugestão de que as díades gay e lésbica funcionam como "hipérboles de gênero" (1993:73), pergunto-me se suas diferenças com respeito à estabilidade dos laços conjugais não são creditáveis precisamente à associação entre masculino e circulação (Heilborn fala explicitamente em "caça sexual"), e entre feminino e vínculo.

${ }^{17}$ É notável, em vários depoimentos da pesquisa Gravad, o quanto o desemprego ou a impossibilidade de sustentar a família afeta a auto-estima do homem. É usual, por exemplo, o procedimento de os entrevistados subestimarem a ajuda de outros familiares [sobretudo os da parceira, mesmo quando são eles que a abrigam com a(s) criança(s)], atribuindo, unicamente a si próprios, o sustento das mesmas.

${ }^{18} \mathrm{O}$ conceito de cismogênese comporta também a variante simétrica que pressupõe uma relação fundada em semelhanças, ou seja, uma relação na qual são trocados bens com um mesmo conteúdo. Esta variante seria assim mais pertinente para a análise de relações fundadas no valor da "igualdade".

${ }^{19}$ Mariza Peirano chamou a minha atenção para a "bricolagem", implícita no texto, entre Dumont e Bateson: enquanto o primeiro propõe a hierarquia entre opostos, Bateson dá movimento a eles. Pode-se ainda agregar que neste "movimento" está contemplado o dilema potencial que subjaz sistemicamente a relações fundadas em diferenças. De fato, o autor tematiza como a conformação exageradamente hierárquica de uma relação (no caso, entre homem e mulher) — justo porque assentada na diferença radical e na complementaridade — pode "patologizar-se" na forma de uma cismogênese escalonante. Restaria cogitar em que medida esse ponto de vista nutrese nos deslizes igualitários de Bateson [ver nota 20]. Para os dilemas que acometem as relações igualitárias de gênero, ver Salem 1989:35-36.

${ }^{20}$ Parece-me haver por vezes na análise de Bateson sobre a cismogênese complementar a intromissão sutil de premissas igualitárias. E creio ser este viés o responsável pela idéia de que a radicalização das especializações de gênero é capaz de "destruir o sistema". Em outras passagens, contudo, Bateson contorna essa distorção analítica; por exemplo, quando destaca a importância do contexto valorativo no qual estão imersas estas relações: "o aspecto de ethos do comportamento é fundamental para a cismogênese, e devemos considerar, menos o conteúdo desse comportamento, e mais a ênfase emocional de que ele se vê revestido no seu contexto cultural" (1958:183).

${ }^{21}$ Um informante da pesquisa Gravad, convencido de que suas três parceiras sucessivas teriam engravidado para "prendê-lo", concluía: "mas elas não vão conseguir: continuo livre, leve e solto" (Salem 2004:59).

${ }^{22}$ Segundo Mary Catherine Bateson, esta foi a questão teórica que seu pai se colocou ao deparar-se com o agudo contraste de gêneros entre os Iatmul (1994:87). 
${ }^{23}$ Bateson endossaria esta interpretação. Ao referir-se à progressão da cismogênese, ela aventa a possibilidade de que "um equilíbrio será alcançado quando as forças de mútua dependência forem equivalentes à tendência cismogênica" (1958:196-197).

${ }^{24}$ Sua tradução mais perfeita encontra-se no que já designei de "casal igualitário". Ver Salem 1987 e 1989.

${ }^{25}$ Esta reciprocidade sem dúvida existe, mas nela imiscuem-se tensões - sobretudo entre os afins. Nota-se, em entrevistas da pesquisa Gravad, o incômodo dos informantes diante das "cobranças" que a parentela da parceira lhes fazia em virtude de o casal e eventualmente a(s) criança(s) viverem sob seu teto.

${ }^{26}$ As considerações que se seguem dizem respeito a um momento mais avançado do ciclo vital das mulheres, justo quando seus filhos atingem a idade adulta e quando elas, em virtude da idade avançada, têm mais dificuldade em prover seu sustento. Mais uma vez impõe-se a relevância da variável tempo reclamada por Leal.

${ }^{27}$ Disponho de informações etnográficas insinuadoras sobre o que se passa entre essas "duas mulheres". A aparição da nora na cena familiar pode ameaçar as esperanças da mãe na incondicionalidade e/ou na permanência de seu filho-eleito (ver Salem 1981:90-92). Foi referindo-se a esta nova concorrente que uma das minhas informantes definiu-se como se estivesse "com a venda nos olhos". As noras, por seu lado, expressam clara consciência da intensa lealdade do seu parceiro para com a mãe: "ele mora comigo [há 15 anos], mas tem a família dele: a mãe dele e o pessoal dele. Eu sei que ele não vai me largar, mas eu sei lá, pode um dia me largar" (idem:83). Há, em suma, notáveis fricções na relação nora/sogra que reportam ao instigante tema da competição entre mulheres, de gerações diferentes, pelos favores de um mesmo homem.

${ }^{28}$ As letras de "Trem das Onze" (Adoniran Barbosa) e "Coração Materno" (Vicente Celestino) são o avesso complementar da outra: a primeira fala da incondicionalidade do amor filial, enquanto a segunda canta a incondicionalidade do amor materno. O pano de fundo de ambas é, novamente, a disputa entre mulheres - sogra e nora - pelo mesmo homem, e/ou o conflito de lealdades por ele experimentado.

${ }^{29}$ Esta hipótese dessubstancializa a identidade masculina ao pressupor que suas qualidades de hierárquico, relacional, individuado etc. sofrem retraduções em função do "valor" e da "situação" em que se fazem operar. A conclusão coaduna-se, assim, com o primado da situacionalidade que Duarte (1986) destaca como implicado na "teoria da hierarquia" de Dumont.

${ }^{30}$ Esta idéia, ao mesmo tempo em que impõe qualificar a tese da "expulsão" do homem da casa, tangencia a estabelecida por Aragão (1983), que postula a ausência de um processo iniciático masculino em relação ao doméstico. Interessante lembrar que o autor se referia, então, aos estratos médios brasileiros. 
${ }^{31}$ Já desenvolvi esta proposta para o princípio igualitário no qual se funda a cosmologia individualista (ver Salem 1987:268-274).

${ }^{32}$ Esta proposta encontra eco, por exemplo, em Simmel: "muito do que somos levados a representar como sentimentos mistos, como resultado de motivações diversas [...] são inteiramente autoconsistentes. Mas, faltando freqüentemente ao intelecto um paradigma para tal unidade, ele o constrói como resultado de vários elementos" (1971:77-78). Alguns trabalhos de DaMatta exploram precisamente esse veio analítico (ver DaMatta 1979).

\section{Referências bibliográficas}

ARAGÃO, Luiz Tarlei. 1983. "Em nome da mãe". In: B. Franchetto; M. L. Cavalcanti e M. L. Heilborn (orgs.), Perspectivas antropológicas da mulher, 3. Rio de Janeiro: Zahar. pp.109-145.

BARROSO, Carmem. 1978. "Sozinhas ou mal acompanhadas: a situação da mulher chefe de família". Trabalho apresentado no Seminário: A Mulher na Força de Trabalho na América Latina, IUPERJ. Ms.

BATESON, Gregory. 1958. "Ethological contrast, competition and schismogenesis (cap. XIII). In: Naven. Stanford: Stanford University Press. 2.ed. pp.171-197.

BATESON, Mary Catherine. 1994. With a daughter's eye: a memoir of Margaret Mead and Gregory Bateson. New York: HarperPerennial.

DAMATTA, Roberto. 1979. Carnavais, malandros e heróis. Rio de Janeiro: Jorge Zahar.

DEBATE. "Sexualidade e ciências sociais: perspectivas e paradigmas no fim do milênio". 1999. In: M. L. Heilborn (org.). Sexualidade: o olhar das ci- ências sociais. Rio de Janeiro: Jorge Zahar Editor. pp. 59-74.

DUARTE, Luiz Fernando Duarte. 1986. Da vida nervosa nas classes trabalhadoras urbanas. Rio de Janeiro: Jorge Zahar/CNPq.

.1987. "Pouca vergonha, muita vergonha: sexo e moralidade entre as classes trabalhadoras urbanas". In: J. S. Leite Lopes (org.). Cultura e identidade operária. Rio de Janeiro: UFRJ/Marco Zero. pp. 203-226.

2005. "Ethos privado e justificação religiosa. Negociações da reprodução na sociedade brasileira". In: M. L. Heilborn, L. F. D. Duarte, M. Lins de Barros, C. Peixoto (orgs.), Sexualidade, família e ethos religioso. Rio de Janeiro: Garamond. pp. 137-176.

HEILBORN, Maria Luiza. 1993. "Gênero e hierarquia: a costela de Adão revisitada". Estudos Feministas, 1(1):50-82.

. 1999. "Construção de si, gênero e sexualidade". In: M. L. Heilborn (org.), Sexualidade: o olhar das ci- 
ências sociais. Rio de Janeiro: Jorge Zahar. pp. 40-58.

2004. Dois é par: gênero e identidade em contexto igualitário. Rio de Janeiro: Editora Garamond.

\& GOUVEIA, Patrícia Fernanda.

1999. "'Marido é tudo igual': mulheres populares e sexualidade no contexto da Aids". In: R. Barbosa e R. Parker (orgs.), Sexualidades pelo avesso. São Paulo: Editora 34. pp. 175-213.

LEAL, Ondina \& BOFF, Adriane de Mello. 1996. "Insultos, queixas, sedução e sexualidade: fragmentos de identidade masculina em uma perspectiva relacional". In: R. Parker e R. Barbosa (orgs.), Sexualidades brasileiras. Rio de Janeiro: Relume Dumará. pp. 119-135.

SALEM, Tania. 1981. "Mulheres faveladas: 'com a venda nos olhos'". In: B. Franchetto; M. L. Cavalcanti e M. L. Heilborn (orgs.), Perspectivas antropológicas da mulher, 1. Rio de Janeiro: Zahar. pp. 49-99.

. 1985. "Família em camadas médias: uma revisão da literatura recente". Boletim do Museu Nacional, 54:1-29 (Nova Série - Antropologia). Republicado com o título "Família em camadas médias: uma perspectiva antropológica". Boletim Informativo e Bibliográfico de Ciências Sociais, 21:25-39, 1986.

1987. Sobre o "casal grávido": incursão em um universo ético. Tese de Doutorado, PPGAS/MN/UFRJ.

1989. "Casal igualitário: princípios e impasses". Revista Brasileira de Ciências Sociais, 3(9):24-37.

1991. "O individualismo libertário no imaginário social dos anos 60". Physis - Revista de Saúde Coletiva, 1(2):59-75.

2004. "'Homem... já viu, né?': representações sobre sexualidade e gênero entre homens de classe popular". In: M. L. Heilborn (org.), Família e sexualidade. Rio de Janeiro: FGV Editora. pp. 15-61.

SIMMEL, Georg. 1971. On individuality and social forms. Chicago: The University of Chicago Press.

TORRES, Marieze R. 2002 [1999]. "Sexo, prazer e dor: vivências sexuais na fala de adolescentes pobres de Salvador". In: R. Barbosa; E. Aquino; M. L. Heilborn; E. Berquó (orgs.), Interfaces. Gênero, sexualidade e saúde reprodutiva. Campinas: Ed. Unicamp. pp. 49-83.

VELHO, Gilberto. 1973. A utopia urbana. Rio de Janeiro: Zahar.

ZALUAR, Alba. 1984. A máquina e a revolta. São Paulo: Brasiliense. 
Resumo

O artigo discute uma das premissas centrais do paradigma hierárquico: o princípio da reciprocidade que informa a relação entre homens e mulheres nas classes populares. Reclamando de uma homologia indevida entre este modelo interpretativo e o ethos feminino, sugere que uma tensão estrutural permeia a relação entre gêneros, e que ela encontra formulação sintética na equação: pendor feminino para o vínculo $\mathrm{x}$ vocação masculina para circular entre mulheres. Argumenta que estas inclinações simbólicas desencontradas são inerentes à própria fabricação do feminino e do masculino nesse contexto moral, e que são constitutivas do sistema. Recorre ao conceito de cismogênese complementar de Bateson tanto para iluminar a dinâmica da aludida tensão, quanto para especular sobre os fatores que inibem a escalada do processo cismogênico em direção ao colapso total do sistema. $\mathrm{O}$ artigo propõe que a tensão endêmica entre os gêneros deve ser considerada como em convivência com o preceito da reciprocidade em um mesmo plano de relevância analítica.

Palavras-chave: Classes trabalhadoras urbanas, Tensões entre gêneros, Relações familiares, Matrifocalidade, Paradigma holista.

\section{Abstract}

The article calls into question one of the main assumptions of the hierarchical paradigm, i.e the principle of reciprocity as something which dominates relationships between working class men and women. Claiming that there is an undue homology between this interpretative model and the feminine ethos, it argues that structural tension pervades the relationship between the genders. This tension can be synthetically phrased as an opposition: feminine permanency vs. masculine impermanency. The article asserts that these disparate symbolic dispositions underlie the construction of each gender within this particular moral context and that they are a constitutive part of the system. The article draws on Bateson's concept of complementary schismogenesis both to illuminate the dynamics of this tension as well as to speculate about factors that hinder the escalation of the schismogenic process, thus preventing the total breakdown of the system. The paper concludes by stating that structural tension between the genders should be placed on the same level of analytical relevance as the principle of reciprocity.

Key words: Urban working class, Intergender tension, Family relations, Matrifocality, Wholistic paradigm. 